\title{
Comparison Of The Frequency And Effectiveness Of Positive And Negative Reinforcement Practices In Schools
}

\author{
Hukam Dad, National University of Modern Languages, Pakistan \\ Riasat Ali, University of Science and Technology, Pakistan \\ Muhammad Zaigham Qadeer Janjua, University of Science and Technology, Pakistan \\ Saqib Shahzad, University of Science and Technology, Pakistan \\ Muhammad Saeed Khan, University of Hazara, Haripur Campus, Pakistan
}

\begin{abstract}
The major purpose of the study was to compare the frequency and effectiveness of positive and negative reinforcement practices deployed by teachers in boys' and girls' secondary schools in urban and rural areas. It was hypothesized that there would be no difference in use of reward and punishment by teachers in secondary schools in urban and rural areas with respect to their frequency and effectiveness. The results of this study brought out a clear picture of the reward and punishment practices being followed in schools, which may serve as a useful tool for improving these practices that influence development of students' desired behaviour. The population of the study comprised of the teachers serving in government secondary schools of Punjab. A sample of 1,000 teachers (200 from district Rawalpindi, 150 from district Attock, 200 from district Lahore, 150 from district Gujranwala, 150 from district Multan, and 150 from district Khanewal) was randomly selected in such a way that the proportion of rural and urban boys' and girls' secondary school teachers was evenly balanced. In order to collect data from sample teachers, a comprehensive questionnaire was developed and personally administered. The data obtained was tabulated, analyzed and interpreted by using appropriate descriptive and inferential tests of significance, such as one-way chi-square and two-way chi-square. The level of significance was 0.05. On the basis of results and discussion, it was concluded that the teachers of urban schools had better knowledge of using reward and punishment with respect to their frequency and effectiveness as well. There should be a countrywide program to train teachers according to the demands of the new era.
\end{abstract}

Keywords: reinforcement, positive \& negative reinforcement, stimulus, achievement

\section{INTRODUCTION}

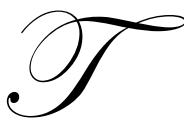

eachers play the most important and practical role in education. They are said to be the builders or architects of a nation. The teacher is the central $\log$ in the machinery of education. The quality and worth of teachers determine the quality of education (Slavin, 1997). Teaching facilitates learning. Learning is a complex phenomenon that has been explained differently. Skinner, a behavioural psychologist and founder of operant conditioning, views operant conditioning as a form of learning in which the consequences of behaviour lead to changes in the probability of that behaviour's occurrence. The consequence (rewards or punishments) are contingent on the organism's behaviour (Halonen, 1996).

According to Madsen and Madsen (1970), behavior that goes unrewarded will extinguish the thought that the teacher must watch the student carefully to determine the payoff. The teacher must also recognize individual 
differences; the payoff is often different for each child. For example, students A, B and C talk in class. After many warnings the teacher finally sends them to the principal's office. This is just exactly what student A wanted; he finally managed to goad the teacher into "punishing" him. Student B just liked to make the teacher angry. Every time she got stern it just "broke him up." He knows he was bothering her, and he enjoyed her distress-"Wow! She gave me such stern looks." Student C did not care about the teacher or the principal. He did care about students A and B. Every time he talked, they listened. On the way to the principal's office, student A filled the others in. "Listen, the principal sits you down and comes and comes on with all this 'You've got to be a good boy' stuff. Man, the last time I was in there I really had him snowed. Besides, he never checks to see if you go back to the class, they will continue to talk-even more.

Child (1993) gives importance of rewards in the teaching/learning process as "the rewarding of appropriate behavior is bread and butter to the teacher." Lepper and Greene (1978) mention that the use of "reinforcement" in the vocabulary of instrumental conditioning was promoted in the mid-1930, particularly by Skinner and primarily as a substitute for the traditional term "reward," whose very age tainted it with the suspicion of mentalism. Mentalism notwithstanding, "reward" was more neutral than "reinforce," for while a reward simply names a class of events that have some effect on the organism, "reinforcement" implies what the effect is namely a strengthening.

"This serves as a reward or - to use a term which is less likely to be misunderstood - 'reinforcement' for the desired behaviour" (Skinner, 1948). "Good things are positive reinforcers... The things we call bad... are all negative reinforcers, and we are reinforced when we escape from or avoid them" (Skinner, 1957).

By the second definition, reinforcers are rewards that are delivered contingent upon the occurrence of some desired response. The first and second definitions are mutually compatible and consistent with the layman's view of rewards; i.e. rewards are good things that can be obtained as a result of good behaviour.

By Skinner's third definition, reinforcers must reinforce or strengthen behaviour. This definition is Skinner's favorite for scientific purposes. A reinforcer is any stimulus event that follows an operant response and thereby increases the strength (or probability of occurrence) of that response. Response rate provides the usual performance measure of increased response probability.

Skinner (1953) identifies two main classes of reinforcers - positive and negative. Positive reinforcers increase response probability by being added to the situation; negative reinforcers increase response probability by being removed. Positive reinforcers are those desired, sought-after stimuli, such as food, praise and money that we ordinarily call rewards.

The main purpose of giving punishments and rewards is to decrease or increase the behaviour of the learner. Punishment; i.e. presenting an unpleasant reinforcer after the occurrence of undesirable response, at times does not help in stopping the undesirable behaviour and reward; i.e. presenting something pleasant after the occurrence of desirable behavior, does not often result in enhancing the performance of the students. The basic reason behind the yielded circumstances is that teachers are not well familiar with different types of rewards and various kinds of punishments along with their effective use. Teachers are not fully aware of the appropriate use of reward and punishment techniques for the desired change in character, behaviour and performance of the students.

Often the teachers inadvertently select and use inappropriate types of rewards and punishments for the students as they are devoid of the knowledge of modern behaviour psychology. Therefore, in order to bring about change into behaviour and learning of the students, the use of modern knowledge about behaviour modification techniques is necessary so that deterioration in the quality of education and behaviour may be improved.

According to Woolfolk (1998), punishment is, at best, a means of the suppressing behavior either by the presentation of something negative or by the removal of something positive. Punishment is a very popular method for influencing behavior in schools. According to Nairne (2003), the term punishment is used to refer to consequences that decrease the likelihood of responding. Like reinforcement, punishment comes in two forms: positive and negative. 
Methuen (1987) argues that to spare the rod is to spoil the child, and there is very good reason to believe this. However, punishment is rarely the best remedy for problems of this nature. According to Witting et al. (1984), punishment is a situation where an organism withholds a response to keep from experiencing an aversive stimulus. There is no specific discriminative stimulus involved.

1. Once begun, punishment must continue to remain effective. When punishment is removed, the behavior soars to a level higher than the original.

2. The more severe the punishment, the more the behavior is suppressed.

3. The sooner the punishment follows the undesirable behavior, the more effective it will be.

4. Once delivered, punishment should be the same for each instance of misbehavior.

5. Punishment can condition fear to all stimuli present when punishment is delivered.

Woolfolk (1998) comments upon corporal punishment as "Corporal punishment also presents a physical danger to the child, who may be seriously hurt if the punishment is too severe or administered in dangerous ways, such as by shaking the child, which could cause a whiplash injury. Child abuse is simply not acceptable in schools, even though it occurs with a fairly high frequency under the guise of discipline. A major danger in the administration of corporal punishment is that the punishment may not be administered in a calm and objective manner keeping in mind the goal of suppressing or eliminating undesirable behaviour. Instead, the administrator of corporal punishment is frequently angry with the child. The danger is that the adult could easily lose control and administer extremely severe punishment out of this anger, causing physical and psychological damage to the child and accomplishing nothing with regard to the child's misbehaviour."

Jenson et al. (1988) comment upon punishment as presenting a consequence (usually called a stimulus) after a behaviour or response which can have three effects on the likelihood of that behaviour occurring again. Punishment always decreases the frequency of behaviour, unless it is already very low. Procedures that involve the presentation or removal of stimuli (consequences) after behaviour and have no effect on the frequency of the behaviour do not have a particular designation. Both reinforcement and punishment can involve either the presentation of a stimulus or the removal of a stimulus relatively soon after some behaviour.

Nairne (2003) is of the view that punishment can also produce undesirable side effects, most notably anger, resentment, and aggression. Studies with animals in the laboratory have shown that aggressive behaviour is often a consequence of punishment procedures. Animals that are shocked together in the same experimental context will often attack one another throughout the shock duration (Domjan, 1976).

Parents who punish their children regularly, without alternative reinforcement, invite future resentment and a loss in the quality of the relationship with their child (Jenson et al., 1988). Few psychologists deny that punishment can be an effective means of stopping behaviour, and it may even be a desirable consequence in some circumstances (e.g., when the child runs into the street or sticks a fork into an electrical outlet). But punishment alone is rarely a sufficient technique; it must be supplemented with alternative strategies for behaving, which provide the opportunity for a little tender loving care (positive reinforcement).

Kazdin (2001) says that punishment is the presentation or removal of a stimulus or event after a response, which decreases the likelihood or probability of that response. This definition is somewhat different from the everyday use of the term. In everyday life, punishment refers to a penalty imposed for performing a particular act. For example, misbehaving children are "taught a lesson" by undergoing pain, sacrifice, or loss of some kind (slap, harsh reprimand, loss of privilege). Criminals may receive penalties (fines, probation and incarceration) based on the acts they have committed. Yet, punishment, in the technical sense, is defined solely by the effect on behaviour. The above examples, although called punishment in everyday life, might not have any effects on the likelihood of future behaviour. In behaviour modification, punishment is operative only if the likelihood of the response is reduced; that is, a punishing event is defined by its suppressive effect on the behaviour that it follows. 


\section{Rationale of the Study}

Among these duties assigned to teachers and are obligatory for him to perform efficiently, his use of reward and punishment had been of much concern in western countries, but was not still having the focus of much attention in Pakistan. Therefore, it was the dire need of the day to be researched upon. The researcher took initiative in the perspective of Pakistan with a study aiming at "comparing the frequency and effectiveness of rewards and punishments used in boys' and girls' secondary schools in urban and rural areas".

\section{Significance of the Study}

The learning process substantiated the importance and significance of Skinner's Operant Conditioning, which had two main factors - positive and negative reinforcement practices. The results of the study indicated which one would be more important and an effective tool for learning. Often the teachers inadvertently select and use inappropriate types of rewards and punishments for the students as they are devoid of the knowledge of modern behaviour psychology. Therefore, in order to bring about change into behaviour and learning of the students, the use of modern knowledge about behaviour modification techniques is necessary so that deterioration in the quality of education and behaviour may be improved. The results of the study may call for constant and appropriate use of rewards and punishments in the classroom at the grass root level in order to make the teaching/learning process more befitting in such a manner that education and personality building of students in the form of socialization carried out side-by-side.

\section{Statement of the Problem}

Rewards and punishments are mostly used in every sphere of the world and their use in the teaching/learning process is very extensive and unavoidable. What are the most appropriate ways of presenting rewards and giving punishment to modify students' behaviour and enhance the quality of the teaching/learning process? This area of effectiveness of reward and punishment had been extensively investigated in the west, yet it was the need of the day to be researched upon in the context of Pakistan. There was great need of examining the pervasiveness of reward and punishment practices in schools and their effectiveness in modifying students' behaviour in the classroom, as there had been done a little work in this field in Pakistan.

\section{Objectives of the Study}

The objectives of this research study included:

1. Compare the frequency and effectiveness of rewards and punishments used in boys' and girls' secondary schools in urban and rural areas of Punjab.

2. Recommend effective use of reward and punishment strategies in the classroom.

\section{Delimitation} Punjab.

The research was delimited to government secondary schools in urban and rural areas of six districts of

\section{Hypothesis}

It was hypothesized: "there was inappropriate use of rewards and punishmentsin secondary schools."

\section{Research Methodology}

The major purpose of the study was to compare the frequency and effectiveness of rewards and punishments used in boys' and girls' secondary schools in urban and rural areas. Research methodology of this study includes a description of the population of all the secondary school teachers working in the government high schools in Punjab constituted the population of the study. One thousand teachers from all over the Punjab were 
randomly selected as the sample of the study (200 from district Rawalpindi, 200 from District Lahore, 150 from District Attock, 150 from district Gujranwala, and 150 each from Districts Multan and Khenwal). A questionnaire for secondary school teachers was prepared and validated through pilot-testing and was used as the research instrument for the study. The researcher personally (where possible) distributed the questionnaires to the respondent and through others, where required, and collected and received the responses. The researcher received all the responses, so the response percentage was 100 percent.

\section{Analysis of Data}

This section deals with analysis and interpretation of data obtained through questionnaires as research tools.

Table 1: You offer punishment without being furious

\begin{tabular}{|c|c|c|c|c|c|c|c|}
\hline & $\mathbf{A}$ & O & ST & AN & $\mathbf{N}$ & Total & $x^{2}$ \\
\hline $\begin{array}{l}\text { Urban } \\
\text { teachers }\end{array}$ & $\begin{array}{c}182 \\
36.40 \% \\
\end{array}$ & $\begin{array}{c}102 \\
20.40 \% \\
\end{array}$ & $\begin{array}{c}66 \\
13.20 \% \\
\end{array}$ & $\begin{array}{c}26 \\
5.20 \% \\
\end{array}$ & $\begin{array}{c}124 \\
24.80 \% \\
\end{array}$ & 500 & \multirow[t]{2}{*}{34.83} \\
\hline $\begin{array}{l}\text { Rural } \\
\text { teachers }\end{array}$ & $\begin{array}{c}108 \\
21.60 \%\end{array}$ & $\begin{array}{c}97 \\
19.40 \%\end{array}$ & $\begin{array}{c}109 \\
21.80 \%\end{array}$ & $\begin{array}{c}42 \\
8.40 \%\end{array}$ & $\begin{array}{c}144 \\
28.80 \%\end{array}$ & 500 & \\
\hline
\end{tabular}

Table 1 indicates that the obtained $\chi^{2}$ value is greater than the critical value at 0.05 level. Therefore, the frequency of responses of urban teachers, as compared to rural teachers, regarding the statement "they 'always' offer punishment without being furious" differed significantly in favor of urban teachers.

Table 2: Students get reward soon after the good behaviour

\begin{tabular}{|l|c|c|c|c|c|c|c|}
\hline & $\mathbf{A}$ & $\mathbf{O}$ & $\mathbf{S T}$ & $\mathbf{A N}$ & $\mathbf{N}$ & Total & $\boldsymbol{\chi 2}$ \\
\hline Urban & 232 & 132 & 120 & 11 & 5 & 500 & $19.25 *$ \\
teachers & $46.40 \%$ & $26.40 \%$ & $24.00 \%$ & $2.20 \%$ & $1.00 \%$ & 500 \\
\hline Rural & 301 & 101 & 86 & 8 & 4 & $0.80 \%$ & \\
teachers & $60.20 \%$ & $20.20 \%$ & $17.20 \%$ & $1.60 \%$ & $\chi^{2}$ at 0.05 level $=9.49$ \\
*Significant
\end{tabular}

Table 2 indicates that the obtained $\chi^{2}$ value is greater than the critical value at 0.05 level. Therefore, the frequency of responses of urban and rural teachers regarding the statement "they 'always' reward students soon after the good behavior" differed significantly in favor of rural teachers.

Table 3: Students negative reinforcement immediately after their wrong behaviour

\begin{tabular}{|l|c|c|c|c|c|c|c|}
\hline & $\mathbf{A}$ & $\mathbf{O}$ & $\mathbf{S T}$ & $\mathbf{A N}$ & $\mathbf{N}$ & Total & $\boldsymbol{\chi 2}$ \\
\hline Urban & 87 & 168 & 159 & 58 & 28 & 500 & $30.9 *$ \\
teachers & $17.40 \%$ & $33.60 \%$ & $31.80 \%$ & $11.60 \%$ & $5.60 \%$ & & \\
\hline Rural & 112 & 183 & 103 & 41 & 61 & 500 \\
teachers & $22.40 \%$ & $36.60 \%$ & $20.60 \%$ & $8.20 \%$ & $12.20 \%$ & \\
*Significant
\end{tabular}

Table 3 shows that the obtained $\chi^{2}$ value is greater than the critical value at 0.05 level. Thus, the frequency of responses of urban and rural teachers regarding the statement "they 'never' punish students immediately after their wrong behavior" differed significantly in favor of urban teachers. 
Table 4: Equal positive reinforcement to the weak and shining students after their desirable behavior

\begin{tabular}{|l|c|c|c|c|c|c|c|}
\hline & A & O & ST & AN & N & Total & $\chi \mathbf{2}$ \\
\hline Urban & 136 & 242 & 49 & 39 & 34 & 500 & $84.04 *$ \\
teachers & $27.20 \%$ & $48.40 \%$ & $9.80 \%$ & $7.80 \%$ & $6.80 \%$ & \\
\hline Rural & 245 & 120 & 77 & 21 & 37 & 500 \\
teachers & $49.00 \%$ & $24.00 \%$ & $15.40 \%$ & $4.20 \%$ & $7.40 \%$ & \\
*Significant
\end{tabular}

Table 4 reflects that the obtained $\chi^{2}$ value is greater than the critical value at 0.05 level. Thus, the frequency of responses of urban and rural teachers regarding the statement "they 'often' reward the weak and shining students equally after their desirable behavior" differed significantly in favor of urban teachers.

Table 5: Equal negative reinforcement to the weak and bright students after their disruptive behavior

\begin{tabular}{|c|c|c|c|c|c|c|c|}
\hline & $\mathbf{A}$ & $\mathbf{O}$ & ST & $\mathbf{A N}$ & $\mathbf{N}$ & Total & $\chi^{2}$ \\
\hline $\begin{array}{l}\text { Urban } \\
\text { teachers }\end{array}$ & $\begin{array}{c}126 \\
25.20 \%\end{array}$ & $\begin{array}{c}73 \\
14.60 \%\end{array}$ & $\begin{array}{c}108 \\
21.60 \%\end{array}$ & $\begin{array}{c}36 \\
7.20 \%\end{array}$ & $\begin{array}{c}157 \\
31.40 \%\end{array}$ & 500 & \multirow[t]{2}{*}{25.37} \\
\hline $\begin{array}{l}\text { Rural } \\
\text { teachers }\end{array}$ & $\begin{array}{c}110 \\
22.00 \%\end{array}$ & $\begin{array}{c}89 \\
17.80 \%\end{array}$ & $\begin{array}{c}138 \\
27.60 \%\end{array}$ & $\begin{array}{c}62 \\
12.40 \%\end{array}$ & $\begin{array}{c}101 \\
20.20 \%\end{array}$ & 500 & \\
\hline
\end{tabular}

Table 5 indicates that the obtained $\chi^{2}$ value is greater than the critical value at 0.05 level. Therefore, the frequency of responses of urban and rural teachers regarding the statement "they 'never' give equal punishment to the weak and bright students after their disruptive behavior" differed significantly in favor of urban teachers.

Table 6: Teachers' feeling after giving punishment to students

\begin{tabular}{|l|c|c|c|c|c|c|c|}
\hline & A & O & ST & AN & N & Total & $\boldsymbol{\chi}$ \\
\hline Urban & 88 & 205 & 52 & 23 & 132 & 500 & $33.25 *$ \\
teachers & $17.60 \%$ & $41.00 \%$ & $10.40 \%$ & $4.60 \%$ & $26.40 \%$ & \\
\hline Rural & 109 & 193 & 85 & 41 & 72 & 500 & \\
teachers & $21.80 \%$ & $38.60 \%$ & $17.00 \%$ & $8.20 \%$ & $14.40 \%$ & \\
\hline
\end{tabular}

Table 6 shows that the obtained $\chi^{2}$ value is greater than the critical value at 0.05 level. Therefore, the frequency of responses of urban and rural teachers regarding the statement "they 'never' remain calm and cool while giving punishment" differed significantly in favor of urban teachers.

Table 7: Punishment is more effective in decreasing undesirable behaviour than reward in increasing desirable behaviour

\begin{tabular}{|l|c|c|c|c|c|c|}
\hline & $\mathbf{A}$ & $\mathbf{O}$ & $\mathbf{S T}$ & $\mathbf{A N}$ & $\mathbf{N}$ & $\mathbf{\text { Total }}$ \\
\hline Urban & 49 & 153 & 185 & 50 & 63 & 500 \\
teachers & $9.80 \%$ & $30.60 \%$ & $37.00 \%$ & $10.00 \%$ & $12.60 \%$ & 52 \\
\hline Rural & 53 & 114 & 199 & 82 & 500 \\
teachers & $10.60 \%$ & $22.80 \%$ & $39.80 \%$ & $16.40 \%$ & $10.40 \%$ & \multicolumn{2}{c|}{$\chi^{2}$ at 0.05 level $=9.49$} \\
\hline
\end{tabular}

Table 7 reflects that the obtained $\chi^{2}$ value is greater than the critical value at 0.05 level. Hence, the frequency of responses of urban and rural teachers regarding the statement "Punishment is 'often' more effective in decreasing undesirable behaviour than reward in increasing desirable behaviour differed" significantly in favor of urban teachers. 
Table 8: Use of punishment immediately, consistently and fairly

\begin{tabular}{l}
\begin{tabular}{|l|c|c|c|c|c|c|c|}
\hline & A & O & ST & AN & N & Total & $\chi^{\mathbf{2}}$ \\
\hline Urban & 118 & 187 & 114 & 35 & 46 & 500 & $21.39 *$ \\
teachers & $23.60 \%$ & $37.40 \%$ & $22.80 \%$ & $7.00 \%$ & $9.20 \%$ & & \\
\hline Rural & 136 & 139 & 165 & 22 & 38 & 500 \\
teachers & $27.20 \%$ & $27.80 \%$ & $33.00 \%$ & $4.40 \%$ & $7.60 \%$ & \\
*Significant
\end{tabular} \\
\hline
\end{tabular}

Table 8 shows that the obtained $\chi^{2}$ value is greater than the critical value at 0.05 level. Hence, the frequency of responses of urban and rural teachers regarding the statement "they 'sometimes' use punishment immediately, consistently and fairly" differed significantly in favor of rural teachers.

\section{DISCUSSION}

The role of education and training is crucial in the Human Resource Development. Education is focused on the training and modification of behavior of human beings accepted in social code. Teachers' role is pivotal to modify the behaviors of students by using the positive and negative reinforcement techniques. In Pakistan, teachers normally use punishment as a tool of learning. Most of the teachers had no skill to use positive and negative reinforcement practices in schools. Further, the Pakistani teachers focused on undesirable behaviors and not on concentrating to strengthen the desirable behaviors. The frequency and intensity of punishment was more in boys' schools compared to girls' schools. Further, it was found that the rural teachers used punishment more frequently than the urban teachers. There was significant difference in the use of reward and punishment in both urban and rural educational institutions. However, it was found that frequency of punishment was much greater than reward, irrespective of geographical and gender dimensions.

Analysis and results of the study showed that urban, as well as rural, teachers were found to be defective and having less knowledge of using rewards and deploying punishment in an effective manner so that their results might be fruitful for students. According to the responses of teachers, the majority of urban teachers were found to be better than rural teachers in giving rewards and punishments frequently and effectively.

\section{CONCLUSIONS}

It was concluded from the findings of the study that urban teachers had better knowledge of giving rewards and punishment regarding their frequency as well as effectiveness. Urban teachers showed better results than rural teachers in comparing frequency and effectiveness of rewards and punishment used in government boys' and girls' secondary schools.

\section{RECOMMENDATIONS}

1. Rural teachers should be given training in using rewards (token system, contingency contract, smile of teacher, etc.) and deploying punishment (extinction, time out, response cost, etc.) in order to make them effective.

2. The research was conducted at the secondary level. Future researches at pre-primary, primary and elementary levels should be done to view the picture from the other side.

3. The questionnaire was used as a research tool. Future researches should be conducted using observational methods to see a more vivid picture.

\section{AUTHOR INFORMATION}

Hukam Dad is currently working as Lecturer Education in Department of Education in National University of Modern Languages in Islamabad Pakistan. Prior to this he served on various administrative posts and as a teacher in Punjab department Pakistan. He has supervised Master and M.Phil dissertations in the several universities of Pakistan. His area of interest is Educational Psychology. He has earned his master and $\mathrm{Ph}$. D degrees from 
University of Arid Agriculture, Pakistan. He is also an active social worker and is working with different national and International NGOs for the eradication of Poverty and illiteracy.

Riasat Ali is presently working as Director, Institute of Education and Research, University of science and Technology, Bannu, N.W.F.P, Pakistan. He has supervised Master and M.Phil dissertations in the universities of Pakistan. His area of expertise is teacher education. He earned doctorate degree from the university of Arid Agriculture, Rawalpindi, Pakistan in the field of modular teaching. The author has rich academic record. Dr. Riasat Ali started his professional carrier as a Science teacher and also worked as a visiting faculty in various varsities of Rawalpindi/Islamabad like Allama Iqbal Open University and Alkhair University etc. He has exposure to National and International seminars, workshops. He is an authority in the field of teacher Education and worked as Resource Person with Govt. and Non Governmental organizations.

Muhammad Zaigham Qadeer Janjua is Assistant Professor, Institute of Education and Research, University of Science and Technology, Bannu, Pakistan. He is a Physicist cum educationist. He is an experienced Researcher, Teacher, Trainer, Planner, Curriculum developer, Curriculum reviewer, Coordinator and administrator. The writer held various key positions in the implementation of projects like Child Friendly Inclusive Education (UNICEF), Strengthening of Teacher Education in Pakistan and development of CD on use of ICT for Science Teachers (UNESCO), Inclusive Education ( International Development Partner, Norwey and Sight Savers international, Early Childhood Education (Childern Resources International, USAID), Use of ICT in Education (Intel) etc. Dr. Zaigham was awarded doctoral degree in the field of curriculum evaluation on Integration of Population, Environment and Drug Education in School curriculum. He is presently supervising 04 students at M.Phil and 03 Students at master level.

Saqib Shahazad is Assistant Professor, Institute of Education and Research, University of Science and Technology, Bannu, NWFF Pakistan, and is presently working as Assistant Professor in University Institute of Education and Research, University of Science and Technology, Bannu, NWFP, Pakistan. He started his carrier as Lecturer in Education at University institute of Education and Research, University of Arid Agriculture, Rawalpindi from Feb, 2006 to Sep, 2007. He was awarded Ph.D (Education) degree in year 2007. The area of his research was A Study to Investigate the Quality of Education at Secondary Level in Punjab. He joined University of Science and Technology Bannu in Sep, 2008 as Assistant. He presented also these papers in national seminars which were acknowledged among the circles of educationist.

Dr. Muhammad Saeed Khan is presently working as HOD, Department of Education, University of Hazara, Haripur Campus, Haripur, NWFP, Pakistan. He has supervised Master and M.Phil dissertations in the several universities of Pakistan. His area of expertise is secondary education. Dr. Muhammad Saeed Khan, in 1984, started his professional carrier as a Science teacher, in 2003, joined Hazara University, Mansehra, NWFP, Pakistan as lecturer, then, in 2004, as Assistant Professor after acquiring doctorate degree from the University of Arid Agriculture, Rawalpindi, Pakistan in the field of intelligence, in 2006, joined University of Science and Technology, Bannu, NWFP, Pakistan.

\section{REFERENCES}

1. Child, D. 1993. Psychology and the teacher. $5^{\text {th }}$ ed. Cassell, London, UK. P. 67.

2. Domjan, M. 1976. Determinants of the enhancement of flavor water intake by prior exposure. Journal of Experimental Psychology: Animal Behavior Processes. 2: 17-27.

3. Halomen, P. T. 1996. Psychological Contents of Behaviour. McGraw Hill Publishing Co., New York, USA. p. 184.

4. Jenson, W. R., H. N. Sloane, K. R. Young and N. Howard. 1988. Applied Behaviour Analysis in Education: A Structured Teaching Approach. Prentice Hall Inc., Eaglewood Cliffs, New Jersey. pp. 25-27.

5. Kazdin, A. E. 2001. Behaviour Modification in Applied Settings. $6^{\text {th }}$ ed. Wadsworth, Australia. pp.3-6.

6. Lepper, M. R. and D. Greene. 1978. The Hidden Costs of Reward: new perspectives on the psychology of human motivation. John Wiley \& Sons, New York. p. 12-15.

7. Madsen, C. H. and C. K. Madsen. 1970. Teaching/Discipline: Behavioural Principles Towards A Positive Approach. Allyn and Bacon, Inc., Boston, USA. pp. 19-30. 
8. Methuen, P. 1987. Psychological Theory and Psychopedagogy Prentice in Teaching. Richard Clay Publisher, London, UK. pp. 22-27.

9. Nairne, J. S. 2003. Psychology: The Adaptive Mind. $3^{\text {rd }}$ ed. Thomson and Wardsworth, Australia. pp. 247253.

10. Skinner, B. F. 1948. Superstition in the pigeon. Journal of Experimental Psychology. 38:168-172.

11. Skinner, B. F. 1953. Science and Human Behaviour. Macmillan Publishers, New York, USA. P.79.

12. Skinner, B. F. 1957. Verbal behavior. Appleton. New York, USA. P. 66.

13. Slavin, S. E. 1997. Educational Psychology: Theory \& Practice. $5^{\text {th }}$ ed. Allyn and Bacon, Boston. pp. 6872.

14. Witting A. F., G. W. William, S. T. David and S. Wagley. 1984. Study Guide to Accompany Psychology: An Introduction. McGraw-Hill Book Company, New York, USA. pp. 62-63.

15. Woolfolk, A. E. 1998. Educational Psychology. $7^{\text {th }}$ ed. Allyn \& Bacon, Boston. pp. 205-220. 
NOTES 